36. What personal attributes would enable you to work well as a member of a multi-disciplinary clinical team?

\section{The method}

Each week, after doing his or her own literature search, the trainee writes an essay on one question, for marking by the tutor. (Depending on the trainee's stage, each question can be approached at various levels of complexity). As far as possible, the substance of the essay is related, in the subsequent discussion, to practical examples. Each session is rounded off with a case history and ten multiple choice questions.

Clearly, this is a fairly intensively interactive activity between the trainee and the tutor. It is evident that the tutor has to be at least as motivated as the trainee to go through with this.

\section{The rewards}

There are rewards on both sides. For the trainee, a sound foundation in psychiatry, in factual knowledge as well as clinical skills, with the attendant enhancement of a faculty more precious than either: the capacity to think. Being able to think skilfully and efficiently is of considerably greater value than stuffing the mind with data.

For the tutor, the reward is the experience of the unique pleasure a part of facilitating the expansion of another person's consciousness, world-view, and general capacity to deal competently with life.

I would like to extend my best wishes to all trainees and tutors who might wish to give this 36-question training programme a try.

\section{Abraham Cowley Unit}

St Peter's Hospital

Chertsey, Surrey KT16 OPZ

\section{Appeal from "Cradle"}

DEAR SIRS

I wish to appeal to your readership for information, news, or submission of articles relevant to the aims and objectives of the organisation I represent in order that we may establish an informative newsletter/magazine.

The organisation is "Cradle" which is a local group of people in Hastings from both professional and non-professional backgrounds who have joined together to pursue their common interest in promoting positive aspects of mental health issues relevant to pregnancy, childbirth, and early parenting. The group is currently moving in the direction of an educational and informative role and hence the emphasis on promoting good communication.

We would be very interested to hear from individuals or groups of similar interest in order to push forwards our aims and objectives, and would invite anyone wishing further information to contact me.

Chairman, "Cradle"

Peter George

clo Holmesdale House

15 Holmesdale Gardens

Hastings, East Sussex TN34 ILY

\section{Wisdom}

A short series of short pieces (with questions)

\section{Knowledge}

"Suppose you and I argue. If you win and I lose, are you indeed right and I wrong? And if I win and you lose, am I right and you wrong? Are we both partly right and partly wrong? Are we both all right or both all wrong? If you and I cannot see the truth, other people will find it even harder."

"Then whom shall we ask to be the judge? Shall I ask someone who agrees with you? If he already agrees with you, how can he be a fair judge? Shall I ask someone who agrees with me? If he already agrees with me, how can he be a fair judge? Shall I ask someone who agrees with both of us? If he already agrees with both of us, how can he be a fair judge? Then if you and I and others cannot decide, shall we wait for still another? Waiting for changing opinions is like waiting for nothing."
"Seeing everything in relation to the heavenly cosmos and leaving the different viewpoints as they are, we may be able to live out our years."

These words were set down by Chuang Tsu, an official in the lacquer garden of Meng in Honan Province around the 4th century BC.

Knowledge has the property of incontrovertibility. Knowledge is what you know.

How do we know what we know?

LARRY CULliford

Aldrington House

Hove Community Mental Health Centre

Hove BN3 4AG 